\title{
The association between health literacy and psychosomatic symptoms of adolescents in China: a cross-sectional study
}

\author{
Shi-chen Zhang ${ }^{1,2^{*}}$ D, Dan-lin Li ${ }^{1}$, Rong Yang ${ }^{1}$, Yu-hui Wan ${ }^{1,2}$, Fang-biao Tao ${ }^{1,2}$ and Jun Fang ${ }^{2,3,4^{*}}$
}

\begin{abstract}
Background: Lower health literacy $(\mathrm{HL})$ has been known to be involved in a range of common mental and physical disorders among adolescent students. Ample studies indicated low HL is associated with a series of chronic diseases even psychological diseases, nevertheless, little is known about this relationship among adolescents. In this context, the study aimed to examine associations between psychosomatic symptoms (physical and psychological symptoms) and $\mathrm{HL}$ in junior and senior high school students in China, and to provide guidance for improving the physical and mental health in Chinese adolescents.

Methods: A total of 22,628 junior and high school students in China were enrolled in this study. $\mathrm{HL}$ and psychosomatic symptoms were measured by self-report validated questionnaires. Multiple linear regression analyses were conducted to examine the associations between six sub-scales of $\mathrm{HL}$ and physical / psychological symptoms.

Results: Multiple linear regression analysis demonstrated that the sub-scales of $\mathrm{HL}$ showed a significantly negative association with physical symptoms and psychological symptoms ( $P<0.05$ for each). Physical symptoms was most strongly associated with $\mathbb{R}(\beta=-0.134)$, followed by SM $(\beta=-0.093), \mathrm{DB}(\beta=-0.059)$, SA $(\beta=-0.058)$ and PA $(\beta=-$ 0.054). No statistically significant difference was found between $\mathrm{HA}$ and physical symptoms $(P>0.05)$. Meanwhile, psychological symptoms were most strongly associated with $\mathbb{R}(\beta=-0.160)$, followed by SA $(\beta=-0.129)$, SM $(\beta=-$ 0.069), $\mathrm{DB}(\beta=-0.031), \mathrm{HA}(\beta=-0.026)$ and $\mathrm{PA}(\beta=-0.021)$.

Conclusion: These results indicated the importance of identifying the association of HL with physical and psychological symptoms, and provided the evidence that lower HL may serve as a critical and independent risk factor for poor health outcomes. Meanwhile, to maintain students' desirable healthy status public health efforts for enhancing their HL level are urgently needed in adolescents.
\end{abstract}

Keywords: Health literacy, Students, Psychosomatic symptoms

\section{Background}

Health literacy (HL), as defined by Ratzan and Parker [1] and adopted by Healthy People $2010[1,2]$ as well as by the Institute of Medicine (IOM) in their 2004 report [3], is "the degree to which individuals can obtain, process,

\footnotetext{
* Correspondence: zhangshichen@ahmu.edu.cn; fangjun@ph.sojo-u.ac.jp 'Department of Maternal and Child Health, School of Public Health, Anhui Medical University, 81th Meishan Road, 230032 Hefei, Anhui Province, People's Republic of China

${ }^{2}$ MOE Key Laboratory of Population Health Across Life Cycle / Anhui Provincial Key Laboratory of Population Health \& Aristogenics, 81th Meishan Road, 230032 Hefei, Anhui Province, People's Republic of China

Full list of author information is available at the end of the article
}

and understand the basic health information and services they need to make appropriate health decisions". HL is dependent on individual and systemic factors, such as communication skills with others, culture, demands of the health care, and so on. Moreover, HL affects people's ability, including engaging in self-care and chronic-disease management, etc. [4]. In addition to basic literacy skills, HL requires knowledge of health topics. People with limited HL often lack knowledge or have misinformation about the body as well as the nature and causes of disease $[3,5]$.

(c) The Author(s). 2019 Open Access This article is distributed under the terms of the Creative Commons Attribution 4.0 International License (http://creativecommons.org/licenses/by/4.0/), which permits unrestricted use, distribution, and reproduction in any medium, provided you give appropriate credit to the original author(s) and the source, provide a link to the Creative Commons license, and indicate if changes were made. The Creative Commons Public Domain Dedication waiver (http://creativecommons.org/publicdomain/zero/1.0/) applies to the data made available in this article, unless otherwise stated. 
From a social-emotional developmental perspective, adolescence is a period of life that may pose special vulnerability to physical and psychological impact factors, such as confusion and greater psychological pressure, even this is the peak period for the onset of mental disorders [6-9]. However, because the emotion regulation mechanism has not yet formed, namely lacking the ability to cope with negative emotion, they are prone to many mental and behavioral problems, such as cut class, sub-optimal physical/psychological health status, selfharm, suicide and others. Ample studies indicated low $\mathrm{HL}$ is associated, both directly and indirectly, with a series of adverse health outcomes [10-14], particularly with increased incidence of chronic diseases even psychological diseases, such as diabetes $[15,16]$, asthma [17], cancer [18], depression [19, 20], and schizophrenia [21]. Meanwhile, lower HL has been known to be involved in a range of common mental and physical disorder among adolescent students [21-26].

Research in the field of HL started late in China. The 2013 Health Literacy Survey of Chinese residents tested adolescents of 15 to 24 years old, and the result indicated that only $9.39 \%$ had adequate HL [27]. Ran M et al. suggested that the inadequate HL may contribute to poorer quality of life (QOL) among junior middle school students in Chongqing, China [28]. Nevertheless, most of these studies are based on small populations with a focus on patients with chronic diseases $[15,28]$, the studies using large samples to investigate this relationship among adolescents are few. In this context, in the present study we focused on the Chinese adolescent students' HL, and administered a questionnaire survey among junior and high school students in six cities, China. The aim of this study was to investigate whether lower HL would be an independent risk factor for poor health outcome in Chinese adolescent students, and to provide guidance for improving the physical and mental health in Chinese adolescents.

\section{Methods}

\section{Data collection and sampling}

This study was conducted from November 2015 to January 2016 and was approved by the Ethics Committee of Anhui Medical University (Mar.1, 2014; approval number 20140087). The study was performed in accordance with the Declaration of Helsinki. All selected subjects were informed of the purpose of the study and were assured confidentiality upon receipt of the questionnaire. Consent to participate in the study was recorded in a separate consent form with the questionnaire, and it was confirmed upon completion and return of the questionnaire. This consent procedure was approved by ethics committees. Data were processed at a restricted location using a personal unidentifiable code for each subject.

Multistage stratified cluster sampling was conducted from junior and senior high schools located in 6 cities in China, including both urban and rural regions, as follows: Shenyang (capital of Liaoning Province), Xinxiang (north of Henan Province), Bengbu (Northeastern of Anhui province), Chongqing (one of China's four directcontrolled municipalities), Ulanchap (Central Inner Mongolia Autonomous Region) and Yangjiang (Southwest coast of Guangdong Province). These cities are representative cities in China in terms of economic development and demographic composition, with average population, and they are also where our adolescent health research network is located. Eight schools in each city were selected including one key junior school, one ordinary junior school, one provincial key senior high school, one municipal key senior high school from rural regions and two ordinary junior schools, one ordinary senior high school and one municipal key senior high school from urban regions. Four to six classes were selected from each grade among grade 7 to 12 for investigation.

Approvals from schools, parents and students were obtained before carrying out this survey. Signed informed consent was requested to each participating school, and the students were allowed to participate in the study upon receiving completed written consent form from their parents. The team members explained the purposes and procedures of the study to the students, and provided an opportunity for them to ask questions. The students were allowed to withdraw from the study if they were not willing to participate. Under the supervision of teachers, each participant completed a self-report questionnaire, during 20-30 min in the classroom.

A total of 23,835 students were recruited in this study, participants were from grade 7-12 in junior and senior schools. The mean age of the participants was 15.36 $(S D=1.79)$. In the participating schools, 708 of the 23 , 835 sampled students were excluded from the study because of their absence from school on the day of the survey or reluctance to respond to the questionnaires. Thus, resulting in the receipt of 23,127 (97.0\%) questionnaires, 22,628 (97.8\%) of which were valid (questionnaire with missing data of $>5 \%$ were excluded).

\section{Design of questionnaires}

The questionnaires consist of questions from demographic variables (i.e., gender, grade, registered residence, only child in family, self-reported family economy, father's educational level, mother's educational level, boarding on school days and support from friends), and the Multidimensional Sub-health Questionnaire of Adolescents (MSQA) and the Chinese Adolescent Interactive Health Literacy Questionnaire (CAIHLQ), as described below. 


\section{Instruments}

MSQA which is developed by Tao et al. [29], with high reliability and validity, to evaluate the physical and psychological symptoms, was used in this study. The MSQA contains the following six sub-scales of two domains with total of 71 items: physical symptoms [physical inactivity (11 items), e.g. 'Often feel sleepy and weak'; physical dysfunction (13 items), e.g. 'Often feel a stomachache'; immunity decline (8 items), e.g. 'Recurrent angular cheilitis'] and psychological symptoms [emotional symptoms (17 items), including depression and anxiety symptoms; conduct symptoms (9 items), including paranoid and hostile behaviors; and social adaptation symptoms (13 items), including bad relationships with family and friends]. Each question had 2 selection categories: $1=$ no or last less than 1 month, 2 = lasts for more than 1 month and more. In the data analysis, no symptom and the symptom duration time $<1$ month was assigned to 0 and the others were assigned to 1 . The higher the score, the longer the symptoms lasted and the more serious the physical and psychological symptoms. The MSQA has been reported by various groups to be a valid and reliable method to explore determinants and the current state of Chinese adolescents' psychosomatic health status [30-35]. In this study, the Cronbach's $\alpha$ coefficient for the MSQA was 0.967, and 0.943 and 0.956 for physical and psychological symptoms.

We developed the Chinese Adolescent Interactive Health Literacy Questionnaire (CAIHLQ) [36], and used it to evaluate the adolescents' HL level of this study. The CAIHLQ has been reported to be a valid and reliable measuring tool $[37,38]$. The CAIHLQ consists of 31 questions grouped into 6 domains, as follows: (1) Physical activities (PA) of 6 items (e.g. 'Following a planned exercise program.'); (2) Interpersonal relationship (IR) of 5 items (e.g. 'Taking times with your family or friends.'); (3) Stress management (SM) of 6 items (e.g. 'Balance time between study and play.'); (4) Self- actualization (SA) of 4 items (e.g. 'Feeling each day is very meaningful.'); (5) Health awareness (HA) of 5 items (e.g. 'Constricting sugars and food containing sugar.'); and (6) Dietary behavior (DB) of 5 items (e.g. 'Eating 200-400 g of fresh fruit each day.'). Each item is rated on 5 selection categories (precontemplation, contemplation, preparation, action, and maintenance), and the total score is standardly converted to a score that ranges from 31 to 155 , with lower scores indicating inadequate HL. In this study, internal consistency test showed that the Cronbach's $\alpha$ coefficient was 0.910 , and 0.662 to 0.847 for six sub-scales.

\section{Statistical analysis}

Statistical analysis was performed using SPSS ver. 23.0 for Windows (SPSS, Inc., Chicago, IL). The scores of HL were normally distributed and the variability in the data was homogeneous. The scores of physical and psychological symptoms were not normally distributed, so we performed logarithmic transformation. Cronbach's alpha analysis was performed to determine the reliability of the survey. The Mann-Whitney test, Kruskal-Wallis H test, independent-Samples $t$ Test and a one-way analysis of variance were used to assess group differences with respect to their statistical significance, while Bonferroniadjusted $P$-value were calculated. The linear regression analysis was performed to examine the relationships between six sub-scales of HL and physical / psychological symptoms. Analyses were adjusted to control for key demographic and socioeconomic variables (i.e., gender, grade, registered residence, only child in family, self-reported family economy, parental education and support from friends). Statistical significance was set at $P<0.05$.

\section{Results \\ Univariate analysis}

Table 1 presents the scores of the physical and psychological symptoms by general demographic characteristics. Senior high school students had significantly higher physical and psychological symptoms scores than junior school students $(Z=-14.091$ and $-10.042, P<0.001$ for each), and higher physical and psychological symptoms scores were also found in students of boarding on school days, lower family income, none support from friends and more than one child in family $(P<0.001$ for each). In addition, the results showed significant associations of gender $(Z=-2.625, P=0.009)$, registered residence $(Z=$ - 2.112, $P=0.035)$ and parental education $(Z=-2.298$ and $-2.623, P<0.01$ for each) with psychological symptoms; respondents whose parents had a higher education level had higher scores of psychological symptoms, and adolescents of female and urban had higher psychological symptoms level.

The overall CAIHLQ mean score for all participants was $104.06 \pm 18.68$, among the six sub-scales of HL, the highest mean score was for SM $(21.18 \pm 5.16)$ and IR $(20.73 \pm 3.75)$, and the lowest mean score was for SA $(15.02 \pm 3.62)$ and HA $(14.97 \pm 4.39)$. As shown in Table 2, the students of junior school, urban, non-boarding on school days, higher parental education level, higher family income and more support from friends had higher scores of total HL and six sub-scales than the other groups $(P<0.001$ for each). Only child in family of students had higher scores of the sub-scales PA, SM, $\mathrm{HA}, \mathrm{DB}$ and overall HL than non-one child students $(P<0.01$ for each). Male students had higher scores of the sub-scales PA and DB than female, while the scores of the sub-scales IR and HA were lower than female $(P<0.001$ for each $)$. No significant differences were 
Table 1 Participant characteristics in the current study

\begin{tabular}{|c|c|c|c|c|c|c|c|c|c|c|c|}
\hline \multirow[t]{2}{*}{ Items } & \multirow[t]{2}{*}{$n(\%)$} & \multicolumn{5}{|c|}{ Physical symptoms } & \multicolumn{5}{|c|}{ Psychological symptoms } \\
\hline & & $\bar{M}$ & $P_{25}$ & $P_{75}$ & $x^{2} / Z$ & $P$-value ${ }^{a}$ & $\bar{M}$ & $P_{25}$ & $P_{75}$ & $x^{2} / Z$ & $P$-value ${ }^{a}$ \\
\hline Gender & & & & & -0.188 & 0.851 & & & & -2.625 & 0.009 \\
\hline Male & $10,990(48.6)$ & 1 & 0 & 3 & & & 2 & 0 & 9 & & \\
\hline Female & $11,638(51.4)$ & 0 & 0 & 4 & & & 2 & 0 & 9 & & \\
\hline Grade & & & & & -14.091 & $<0.001$ & & & & -10.042 & $<0.001$ \\
\hline Junior school & $11,993(53.0)$ & 0 & 0 & 3 & & & 2 & 0 & 8 & & \\
\hline Senior high school & $10,635(47.0)$ & 1 & 0 & 4 & & & 3 & 0 & 10 & & \\
\hline Registered residence & & & & & -1.000 & 0.317 & & & & -2.112 & 0.035 \\
\hline Rural & $10,882(48.1)$ & 0 & 0 & 4 & & & 2 & 0 & 9 & & \\
\hline Urban & $11,746(51.9)$ & 0 & 0 & 3 & & & 2 & 0 & 9 & & \\
\hline Boarding on school days & & & & & 13.647 & $<0.001$ & & & & 10.570 & $<0.001$ \\
\hline Yes & $11,320(50.0)$ & 1 & 0 & 4 & & & 3 & 0 & 10 & & \\
\hline No & $11,308(50.0)$ & 0 & 0 & 3 & & & 1 & 0 & 8 & & \\
\hline Household structure & & & & & -5.575 & $<0.001$ & & & & -4.860 & $<0.001$ \\
\hline Only child & $9720(43.0)$ & 1 & 0 & 4 & & & 2 & 0 & 10 & & \\
\hline More than one child & $12,908(57.0)$ & 0 & 0 & 3 & & & 2 & 0 & 9 & & \\
\hline Father's educational level & & & & & -0.626 & 0.531 & & & & -2.298 & 0.022 \\
\hline$<$ High school degree & $13,006(57.5)$ & 0 & 0 & 3 & & & 2 & 0 & 9 & & \\
\hline$\geq$ High school degree & 9424 (41.6) & 0 & 0 & 4 & & & 2 & 0 & 9 & & \\
\hline No father & $198(0.9)$ & & & & & & & & & & \\
\hline Mother's educational level & & & & & -1.230 & 0.219 & & & & -2.623 & 0.009 \\
\hline$<$ High school degree & $14,335(63.4)$ & 0 & 0 & 3 & & & 2 & 0 & 9 & & \\
\hline$\geq$ High school degree & 8105 (35.8) & 1 & 0 & 4 & & & 2 & 0 & 9 & & \\
\hline No mother & $188(0.8)$ & & & & & & & & & & \\
\hline Self-reported family economy & & & & & 308.706 & $<0.001$ & & & & 355.664 & $<0.001$ \\
\hline Bad & $3240(14.3)$ & 2 & 0 & 6 & & & 5 & 0 & 15 & & \\
\hline General & $16,345(72.2)$ & 0 & 0 & 3 & & & 2 & 0 & 8 & & \\
\hline Good & $3043(13.4)$ & 0 & 0 & 3 & & & 2 & 0 & 9 & & \\
\hline Support from friends & & & & & 257.148 & $<0.001$ & & & & 444.541 & $<0.001$ \\
\hline None & $599(2.6)$ & 3 & 0 & 13 & & & 12 & 2 & 24 & & \\
\hline Few & $14,535(64.2)$ & 1 & 0 & 4 & & & 2 & 0 & 10 & & \\
\hline Lot & $7494(33.1)$ & 0 & 0 & 3 & & & 1 & 0 & 7 & & \\
\hline
\end{tabular}

Statistical methods: Mann-Whitney test or Kruskal- Wallis $\mathrm{H}$ test. ${ }^{a}$ is Bonferroni-adjusted $P$-value

found in total HL and others sub-scales by gender (Table 2).

\section{Multiple linear regression analysis}

The total scores of psychosomatic symptoms according to MSQA were abnormally distributed, so we had a logarithmic transformation of the total score. We verified that evaluation of HL by CAIHLQ was indeed related to physical / psychological symptoms. This was determined from a single correlation analysis showing that overall scores of HL $(r=-0.218)$, PA $(r=-0.069)$, IR $(r=-0.221)$, SM $(r=-0.202)$, SA $(r=-0.190)$, HA $(r=-0.107)$ and DB $(r=-0.141)$ were significantly correlated with physical symptoms. Moreover, results from correlation analyses revealed that overall scores of HL $(r=-0.287)$, PA $(r=-0.120)$, IR $(r=-0.282)$, SM $(r=-0.241)$, SA $(r=-0.271), \mathrm{HA}(r=-0.155)$ and DB $(r=-0.143)$ were significantly correlated with psychological symptoms $(P<0.001$ for each, Table 3$)$.

We further carried out multiple linear regression analysis adjusted for key demographic variables (e.g. support from friends, household structure, boarding on school days, self-reported family economy, gender and grade), using logarithmic transformation of total scores of physical / psychological symptoms as a dependent variable, and overall and the six sub-scales 
Table 2 Distribution of average score of HL according to CAIHLQ ${ }^{a}$ based on completed and returned survey questionnaires

\begin{tabular}{|c|c|c|c|c|c|c|c|}
\hline Variables $(n)$ & $\mathrm{PA}$ & $\mathbb{R}$ & SM & SA & $\mathrm{HA}$ & $\mathrm{DB}$ & Overall HL \\
\hline \multicolumn{8}{|l|}{ Gender } \\
\hline Male (10990) & $15.89 \pm 4.93$ & $20.27 \pm 3.97$ & $21.18 \pm 5.35$ & $15.06 \pm 3.72$ & $14.65 \pm 4.56$ & $16.88 \pm 4.25$ & $103.94 \pm 19.83$ \\
\hline Female (11638) & $15.04 \pm 4.36$ & $21.17 \pm 3.47$ & $21.17 \pm 4.97$ & $14.98 \pm 3.54$ & $15.27 \pm 4.22$ & $16.55 \pm 3.40$ & $104.17 \pm 17.53$ \\
\hline$t$ & 13.881 & -18.194 & 0.168 & 1.695 & -10.585 & 6.090 & -0.936 \\
\hline P-value & $<0.001$ & $<0.001$ & 0.860 & 0.090 & $<0.001$ & $<0.001$ & 0.349 \\
\hline \multicolumn{8}{|l|}{ Grade } \\
\hline Junior school (11993) & $16.11 \pm 4.70$ & $20.91 \pm 3.72$ & $21.79 \pm 5.21$ & $15.36 \pm 3.62$ & $15.16 \pm 4.43$ & $17.10 \pm 4.23$ & $106.45 \pm 18.94$ \\
\hline Senior high school (10635) & $14.71 \pm 4.52$ & $20.53 \pm 3.76$ & $20.49 \pm 5.01$ & $14.63 \pm 3.61$ & $14.74 \pm 4.35$ & $16.27 \pm 3.95$ & $101.37 \pm 18.01$ \\
\hline$t$ & 22.844 & 7.678 & 19.206 & 15.180 & 7.182 & 15.210 & 20.598 \\
\hline P-value & $<0.001$ & $<0.001$ & $<0.001$ & $<0.001$ & $<0.001$ & $<0.001$ & $<0.001$ \\
\hline \multicolumn{8}{|l|}{ Registered residence } \\
\hline Rural (10882) & $15.08 \pm 4.47$ & $20.65 \pm 3.71$ & $20.85 \pm 5.10$ & $14.87 \pm 3.61$ & $14.74 \pm 4.33$ & $16.19 \pm 4.10$ & $102.38 \pm 18.15$ \\
\hline Urban (11746) & $15.80 \pm 4.81$ & $20.81 \pm 3.78$ & $21.48 \pm 5.20$ & $15.16 \pm 3.65$ & $15.17 \pm 4.45$ & $17.19 \pm 4.10$ & $105.62 \pm 19.03$ \\
\hline$t$ & -11.738 & -3.386 & -9.232 & -5.967 & -7.373 & -18.209 & -13.081 \\
\hline P-value & $<0.001$ & 0.001 & $<0.001$ & $<0.001$ & $<0.001$ & $<0.001$ & $<0.001$ \\
\hline \multicolumn{8}{|l|}{ Boarding on school days } \\
\hline Yes (11320) & $14.84 \pm 4.39$ & $20.63 \pm 3.66$ & $20.69 \pm 5.00$ & $14.83 \pm 3.55$ & $14.71 \pm 4.32$ & $16.21 \pm 4.00$ & $101.90 \pm 17.81$ \\
\hline No (11308) & $16.07 \pm 4.84$ & $20.84 \pm 3.83$ & $21.67 \pm 5.27$ & $15.22 \pm 3.70$ & $15.22 \pm 4.46$ & $17.21 \pm 4.18$ & $106.23 \pm 19.27$ \\
\hline$t$ & -20.070 & -4.202 & -14.231 & -8.091 & -8.853 & -18.417 & -17.530 \\
\hline P-value & $<0.001$ & $<0.001$ & $<0.001$ & $<0.001$ & $<0.001$ & $<0.001$ & $<0.001$ \\
\hline \multicolumn{8}{|l|}{ Household structure } \\
\hline Only child (9720) & $15.60 \pm 4.79$ & $20.72 \pm 3.89$ & $21.31 \pm 5.23$ & $15.03 \pm 3.69$ & $15.06 \pm 4.58$ & $17.11 \pm 4.15$ & $104.81 \pm 19.20$ \\
\hline More than one child (12908) & $15.34 \pm 4.57$ & $20.75 \pm 3.63$ & $21.08 \pm 5.10$ & $15.02 \pm 3.59$ & $14.90 \pm 4.35$ & $16.41 \pm 4.09$ & $103.49 \pm 18.26$ \\
\hline$t$ & 4.131 & -0.596 & 3.332 & 0.141 & 2.658 & 12.624 & 5.266 \\
\hline$P$-value & $<0.001$ & 0.551 & 0.001 & 0.888 & 0.008 & $<0.001$ & $<0.001$ \\
\hline \multicolumn{8}{|l|}{ Father's educational level } \\
\hline$<$ High school degree (13006) & $14.99 \pm 4.41$ & $20.59 \pm 3.71$ & $20.83 \pm 5.08$ & $14.80 \pm 3.61$ & $14.70 \pm 4.31$ & $16.29 \pm 4.06$ & $102.20 \pm 18.05$ \\
\hline$\geq$ High school degree (9424) & $16.10 \pm 4.90$ & $20.96 \pm 3.75$ & $21.68 \pm 5.20$ & $15.34 \pm 3.61$ & $15.35 \pm 4.48$ & $17.30 \pm 4.11$ & $106.73 \pm 19.01$ \\
\hline No father (198) & - & - & - & - & - & - & - \\
\hline$t$ & -17.695 & -7.321 & -12.180 & -11.022 & -11.079 & -18.256 & -18.116 \\
\hline P-value & $<0.001$ & $<0.001$ & $<0.001$ & $<0.001$ & $<0.001$ & $<0.001$ & $<0.001$ \\
\hline \multicolumn{8}{|l|}{ Mother's educational level } \\
\hline$<$ High school degree (14335) & $14.98 \pm 4.41$ & $20.58 \pm 3.68$ & $20.85 \pm 5.06$ & $14.80 \pm 3.60$ & $14.68 \pm 4.31$ & $16.34 \pm 4.07$ & $102.24 \pm 17.94$ \\
\hline$\geq$ High school degree (8105) & $16.30 \pm 4.96$ & $21.04 \pm 3.79$ & $21.79 \pm 5.24$ & $15.42 \pm 3.63$ & $15.48 \pm 4.50$ & $17.39 \pm 4.12$ & $107.42 \pm 19.27$ \\
\hline No mother (188) & - & - & - & - & - & - & - \\
\hline$t$ & -20.544 & -8.805 & -13.270 & -12.247 & -13.147 & -18.568 & -20.244 \\
\hline$P$-value & $<0.001$ & $<0.001$ & $<0.001$ & $<0.001$ & $<0.001$ & $<0.001$ & $<0.001$ \\
\hline \multicolumn{8}{|l|}{ Self-reported family economy } \\
\hline Bad (3240) & $14.78 \pm 4.69$ & $19.52 \pm 4.32$ & $19.70 \pm 5.40$ & $14.08 \pm 3.96$ & $14.30 \pm 4.53$ & $15.79 \pm 4.30$ & $98.17 \pm 19.99$ \\
\hline General (16345) & $15.35 \pm 4.52$ & $20.87 \pm 3.55$ & $21.26 \pm 5.01$ & $15.06 \pm 3.52$ & $14.97 \pm 4.31$ & $16.71 \pm 4.02$ & $104.23 \pm 17.83$ \\
\hline Good (3043) & $16.70 \pm 5.19$ & $21.30 \pm 3.82$ & $22.33 \pm 5.31$ & $15.80 \pm 3.64$ & $15.63 \pm 4.60$ & $17.66 \pm 4.28$ & $109.43 \pm 19.90$ \\
\hline$F$ & 147.758 & 218.954 & 216.155 & 182.200 & 72.745 & 163.181 & 294.662 \\
\hline P-value ${ }^{a}$ & $<0.001$ & $<0.001$ & $<0.001$ & $<0.001$ & $<0.001$ & $<0.001$ & $<0.001$ \\
\hline
\end{tabular}


Table 2 Distribution of average score of $\mathrm{HL}$ according to CAlHLQ ${ }^{a}$ based on completed and returned survey questionnaires (Continued)

\begin{tabular}{llllllll}
\hline Variables $(n)$ & PA & IR & SM & SA & HA & DB & Overall HL \\
\hline Support from friends & & & & & & & \\
$\quad$ None (599) & $14.13 \pm 5.77$ & $16.21 \pm 5.54$ & $18.13 \pm 6.37$ & $12.66 \pm 4.72$ & $13.87 \pm 5.06$ & $15.06 \pm 5.11$ & $90.05 \pm 20.01$ \\
Few (14535) & $14.94 \pm 4.37$ & $20.37 \pm 3.64$ & $20.67 \pm 5.02$ & $14.66 \pm 3.56$ & $14.77 \pm 4.31$ & $16.45 \pm 4.01$ & $101.86 \pm 17.74$ \\
Lot (7494) & $16.56 \pm 4.92$ & $21.79 \pm 3.35$ & $22.42 \pm 5.05$ & $15.92 \pm 3.46$ & $15.43 \pm 4.48$ & $17.34 \pm 4.18$ & $109.45 \pm 18.43$ \\
F & 331.936 & 867.191 & 406.191 & 447.278 & 74.106 & 165.928 & 613.364 \\
P-value $^{a}$ & $<0.001$ & $<0.001$ & $<0.001$ & $<0.001$ & $<0.001$ & $<0.001$ & $<0.001$ \\
\hline
\end{tabular}

Statistical methods: Independent-Samples $t$ Test or One-Way ANOVA

${ }^{a}$ CAIHLQ, Chinese Adolescent Interactive Health Literacy Questionnaire. Overall HL is the mean score of all 31 items in the six subscales: PA is Physical Activity; IR is Interpersonal Relationships; SM is Stress Management; SA is Self-actualization; HA is Health awareness and DB is Dietary behavior. ${ }^{a}$ is

Bonferroni-adjusted $P$-value

of $\mathrm{HL}$ as independent variables, respectively. The total score and scores of six sub-scales exist in a collinear manner, Table 4 showed the correlation between six sub-scales and physical / psychological symptoms. The models fitted well $(P<0.001$ for each model).

As shown in Table 4, the sub-scales of HL showed a significantly negative association with physical symptoms and psychological symptoms $(P<0.05$ for each). Physical symptoms were most strongly associated with IR $(\beta=-0.134)$, followed by SM $(\beta=-0.093)$, DB $(\beta=-$ $0.059)$, SA $(\beta=-0.058)$ and PA $(\beta=-0.054)$. No statistically significant difference was found between HA and physical symptoms $(P>0.05)$. Meanwhile, psychological symptoms were most strongly associated with IR $(\beta=-$ $0.160)$, followed by SA $(\beta=-0.129)$, SM $(\beta=-0.069)$, $\mathrm{DB}(\beta=-0.031), \mathrm{HA}(\beta=-0.026)$ and PA $(\beta=-0.021)$.

\section{Discussion}

This study is focused on the Chinese adolescent students' $\mathrm{HL}$, examining the associations between psychosomatic symptoms and HL in junior and high school students in
China. As hypothesized, compared with students with higher HL, those with lower HL have shown more physical and psychological symptoms. Associations remained significant after controlling for demographics. Thus, HL appears to be independently associated with certain known predictors of poor health status. Individuals with lower HL might be inclined to have mental disorders and physical illness.

Our findings indicated that the students of junior school, urban, non-boarding on school days, higher parental education level, higher family income and more support from friends had higher scores of total HL and six sub-scales than the other groups, these findings are congruent with results from the previous studies [27, 37, 39]. In the current study, the students of lower family income, none support from friends and non-one child in family had significantly higher physical and psychological symptoms scores, consistent with other studies. It is indicated that parental companionship plays an important role in adolescent health development [30-33]. At the same time, parents in better financial condition will have

Table 3 Correlations between HL with both physical symptoms and psychological symptoms for participants

\begin{tabular}{|c|c|c|c|c|c|c|c|c|c|}
\hline & $\begin{array}{l}\text { Overall } \\
\mathrm{HL}\end{array}$ & PA & IR & SM & SA & $\mathrm{HA}$ & DB & $\begin{array}{l}\text { Physical } \\
\text { symptoms }\end{array}$ & $\begin{array}{l}\text { Psychological } \\
\text { symptoms }\end{array}$ \\
\hline Overall HL & - & & & & & & & & \\
\hline PA & $0.692^{* * *}$ & - & & & & & & & \\
\hline $\mathbb{R}$ & $0.688^{* * *}$ & $0.313^{* * *}$ & - & & & & & & \\
\hline SM & $0.823^{* * *}$ & $0.448^{* * *}$ & $0.567^{* * *}$ & - & & & & & \\
\hline SA & $0.772^{* * *}$ & $0.416^{* * *}$ & $0.346^{* * *}$ & $0.634^{* * *}$ & - & & & & \\
\hline $\mathrm{HA}$ & $0.723^{* * *}$ & $0.429^{* * *}$ & $0.314^{* * *}$ & $0.491^{* * *}$ & $0.453^{* * *}$ & - & & & \\
\hline DB & $0.641^{* * *}$ & $0.336^{* * *}$ & $0.688^{* * *}$ & $0.401^{* * *}$ & $0.354^{* * *}$ & $0.395^{* * *}$ & - & & \\
\hline Physical symptoms & $-0.218^{* * *}$ & $-0.069^{* * *}$ & $-0.221^{* * *}$ & $-\overline{0.202^{* * *}}$ & $-\overline{-}^{* 190^{* * *}}$ & $-\overline{0.107^{* * *}}$ & $-0.141^{* * *}$ & - & \\
\hline $\begin{array}{l}\text { Psychological } \\
\text { symptoms }\end{array}$ & $-0.287^{* * *}$ & $\begin{array}{l}- \\
0.120^{* * *}\end{array}$ & $-\overline{-}^{282^{* * *}}$ & $-\overline{0}^{* 241^{* * *}}$ & $-0.271^{* * *}$ & $-\overline{0}^{* 155^{* * *}}$ & $-0.143^{* * *}$ & $0.518^{* * *}$ & - \\
\hline
\end{tabular}

Overall HL is the mean score of all 31 items in the six subscales: PA is Physical Activity; IR is Interpersonal Relationships; SM is Stress Management; SA is Selfactualization; HA is Health awareness and DB is Dietary behavior. ${ }^{* * *} P<0.001$ 
Table 4 Multiple linear regression for psychosomatic symptoms according to health literacy

\begin{tabular}{|c|c|c|c|c|c|c|c|c|}
\hline \multirow[t]{2}{*}{ Variable } & \multicolumn{4}{|c|}{ Physical symptoms ${ }^{a}$} & \multicolumn{4}{|c|}{ Psychological symptoms ${ }^{b}$} \\
\hline & $B(S E)$ & $95 \% \mathrm{Cl}$ & $\beta$ & $P$-value & $B(S E)$ & $95 \% \mathrm{Cl}$ & $\beta$ & $P$-value \\
\hline$\overline{P A}$ & $-0.005(0.001)$ & $-0.007,-0.003$ & -0.054 & $<0.001$ & $-0.002(0.001)$ & $-0.004,-0.001$ & -0.021 & 0.024 \\
\hline $\mathbb{R}$ & $-0.015(0.001)$ & $-0.017,-0.012$ & -0.134 & $<0.001$ & $-0.019(0.001)$ & $-0.022,-0.017$ & -0.160 & $<0.001$ \\
\hline SM & $-0.008(0.001)$ & $-0.010,-0.006$ & -0.093 & $<0.001$ & $-0.006(0.001)$ & $-0.008,-0.004$ & -0.069 & $<0.001$ \\
\hline SA & $-0.007(0.001)$ & $-0.009,-0.004$ & -0.058 & $<0.001$ & $-0.016(0.001)$ & $-0.019,-0.014$ & -0.129 & $<0.001$ \\
\hline $\mathrm{HA}$ & $0.001(0.001)$ & $0.002,0.003$ & 0.001 & 0.893 & $-0.003(0.001)$ & $-0.005,-0.001$ & -0.026 & $<0.001$ \\
\hline DB & $-0.006(0.001)$ & $-0.008,-0.004$ & -0.059 & $<0.001$ & $-0.004(0.001)$ & $-0.006,-0.002$ & -0.031 & 0.006 \\
\hline$\Delta R^{2}$ & $0.071^{* * *}$ & & & & & 0.110 & & \\
\hline
\end{tabular}

${ }^{a}$ Adjusted for grade, boarding on school days, household structure, self-reported family economy and support from friends; ${ }^{b}$ Adjusted for gender, grade, registered residence, boarding on school days, household structure, parents' educational level, self-reported family economy and support from friends.PA is Physical Activity; IR is Interpersonal Relationships; SM is Stress Management; SA is Self-actualization; HA is Health awareness and DB is Dietary behavior. $\triangle R^{2}$ is coefficient of determination

more time and energy to communicate and support with their children, thus reducing the occurrence and development of their children's physical and psychological problems $[40,41]$.

We found that lower student's HL is associated with higher odds of poor health outcome, even after adjustment for the influence of demographics. Physical symptoms and psychological symptoms were shown to have similar tendencies on the scores of six sub-scales, as well as in the correlations among variables (Tables 3 and 4). The items of six sub-scales are recognized as advantageous factors for achieving a high QOL, by reducing stress and by enhancing relationships, respectively [42].

In this study, the six sub-scales of HL were significantly associated with each factor, showing IR have the highest $\beta$-value, followed by SM, DB, SA and PA. Similar results were found in both physical and psychological symptoms. The interpersonal relationships have been linked not only to mental health but also to morbidity and mortality [43, 44], which is consistent with the current study. Accordingly, interpersonal relationships facilitate healthier behaviors and adherence to medical regimens, which in turn protect the subject from developing the disease [45]. Additionally, other potential mechanisms that might explain how social support can health are related to biological mechanisms, especially the immune-mediated inflammatory processes [46]. Petersen $\mathrm{S}$ et al. reported that recurrent pain symptoms in children, particularly frequent symptoms, should be regarded as a potential general pain disorder rather than merely a localized body disorder, they also reflected psychological stress [47]. Therefore, students with low levels of SM, IR and SA have increased psychological stresses and negative emotions, which will increase the incidence of pain-related items in physical symptoms [48, 49].

Although the mechanism between HL and health outcomes has not been clarified, Bailey SC et al. found through path analysis that HL influences self-efficacy through knowledge, and then directly or indirectly (through physical activity) influences health outcomes [50]. The correlation between the sub-scales of PA and physical and psychological symptoms may be realized through this path in this study. A growing body of evidence indicates that PA can have beneficial effects on physical and mental health in adolescents [51]. The odds for depressive symptoms were lower for those who were physically active in a sports club (OR: 0.40, 95\% CI: $0.30-0.53)$ [52]. It suggests a possible role of social interaction in addition to physical activity per se [52]. Unhealthy dietary behavior (e.g. irregularity of meals and breakfast skipping, etc.) play an important role in developing physical and mental health in adolescents [53]. It has been showed that the association between stress and unhealthy dietary behavior may also be mediated by avoidant coping, and that stress may affect health in an indirect way through unhealthy dietary behaviors [54]. Though the cross-sectional nature of the study limits causal inference, it strongly suggested that interventions for improving adolescent student's HL will reducing their physical and psychological symptoms.

HA is one of the major indicators which reveal a person's knowledge about health problems [55]. In this study, no statistically significant difference was found between HA and physical symptoms, which is worth emphasizing. These students did not feel any desirable degree of health awareness probably because young people do not consider health controls as being necessary issue relating to healthy life in China. Generally, if the individual does not realize his own health problems, he will not make any effort to improve his health [56]. It is thus particularly important for adolescents to not only promote their health, but also have a suitable health awareness [57].

In this study, we selected the participants from both rural and urban regions, considering the difference in the different socioeconomic conditions. Nevertheless, 
only six cities were surveyed, the validity of this study for students in other regions, countries or cultures is not fully clear and need further investigations. We suggest further research with larger study populations and in different regions of the country. It should also be noted that the reliance on self-report measures is a possible limitation in this study, which may be biased in the measuring process. Moreover, another limitation is that both the independent variable and dependent variable are constructs that cannot be measured precisely. Thus, latent variable methods should be applied in the future to account properly for the latent nature of those constructs. Furthermore, the missing students were not included in the survey, and these students may have a lower HL and may have more psychosomatic symptoms. In addition, because the analyses in this study used cross-sectional data, the results may not imply causality but rather demonstrate an independent association between HL and poor health outcomes. Longitudinal studies will be used to clarity temporal relationship of HL to physical/psychological symptoms in the future study.

\section{Conclusion}

Taken together, our results indicated the importance of identifying the correlates of $\mathrm{HL}$ and psychosomatic symptoms, and provided the evidence that HL may serve as a critical and independent risk factor for poor health outcomes. Meanwhile, health guidance and intervention program for adolescent students from school, family and community to enhance their health literacy levels would be effective measures to maintain a desirable healthy status. Additionally, it merits further longitudinal studies to confirm the impact of HL on psychosomatic symptoms, and verify the hypothesis that improving students $\mathrm{HL}$ may be effective in modifying psychosomatic symptoms.

\footnotetext{
Abbreviations

CAIHLQ: Chinese Adolescent Interactive Health Literacy Questionnaire; DB: Dietary behavior; HA: Health awareness; HL: health literacy; IR: Interpersonal relationship; MSQA: Multidimensional Sub-health Questionnaire of Adolescents; PA: Physical activities; SA: Self - actualization; SM: Stress management
}

\section{Acknowledgements}

The authors gratefully acknowledge the project teams, school action teams, and staff and students from the participating schools for their cooperation on-site during the process of data acquisition.

\section{Authors' contributions}

All authors have read and approved the manuscript. Participated in research design and obtained funding: SCZ and FBT. Conducted the analysis and interpretation of data: SCZ, DLL, RY and YHW. Subjects' recruitment and data collection: SCZ, YHW, DLL and RY. Wrote or contributed to the writing of the manuscript: SCZ and JF.

\section{Funding}

We are grateful for the financial support offered by the National Natural Science Foundation of China (grant number 81402699 and 81573512) for the data collection, in writing and publishing the manuscript.

\section{Availability of data and materials}

We could not provide data set publicly because of the ethical restrictions and privacy concerns. However, those data will be available upon request to all interested researchers, in this case, please contact the Ethics Committee of Anhui Medical University (+ 86-551-65161057).

\section{Ethics approval and consent to participate}

Approval for the study was granted by the Ethics Committee of Anhui Medical University (Mar. 1, 2014; approval number 20140087). Any information that could distinguish individual participants was not collected during the data collection process. We had signed informed consent with each participating school, which the students were allowed to participate in the study upon receiving completed written consent form from their parents.

\section{Consent for publication}

Not applicable.

\section{Competing interests}

The authors declare that they have no competing interests.

\section{Author details}

${ }^{1}$ Department of Maternal and Child Health, School of Public Health, Anhui Medical University, 81th Meishan Road, 230032 Hefei, Anhui Province, People's Republic of China. ${ }^{2}$ MOE Key Laboratory of Population Health Across Life Cycle / Anhui Provincial Key Laboratory of Population Health \& Aristogenics, 81th Meishan Road, 230032 Hefei, Anhui Province, People's Republic of China. ${ }^{3}$ Department of Toxicology, School of Public Health, Anhui Medical University, 81th Meishan Road, 230032 Hefei, Anhui Province, People's Republic of China. ${ }^{4}$ Faculty of Pharmaceutical Science, Sojo University, Ikeda 4-22-1, Kumamoto 860-0082, Japan.

Received: 18 April 2019 Accepted: 4 September 2019

Published online: 12 September 2019

\section{References}

1. Ratzan SC, Parker RM. Introduction. In: Selden CR, Zorn M, Ratzan SC, Parker RM, editors. National library of medicine current bibliographies in medicine: health literacy. NLM pub. No. CBM 2000-1. Bethesda: National Institutes of Health, U.S. Department of Health and Human Services; 2000. https://nnlm. gov/initiatives/topics/health-literacy [2019-06-17].

2. U.S. Department of Health and Human Services, Office of Disease Prevention and Health Promotion. National action plan to improve health literacy. Washington (DC): Author; 2010. https://www.healthypeople.gov/202 0/topics-objectives/topic/social-determinants-health/interventions-resources/ health-literacy [2019-06-17].

3. Institute of Medicine (US) Committee on Health Literacy, Nielsen-Bohlman L Panzer AM, Kindig DA, editors. Health Literacy: A Prescription to End Confusion. Washington (DC): National Academies Press (US); 2004.

4. Kefalides PT. Illiteracy: the silent barrier to health care. Ann Intern Med. 1999;130(4 Pt 1):333-6.

5. Paasche-Orlow MK, Parker RM, Gazmararian JA, Nielsen-Bohlman LT, Rudd RR. The prevalence of limited health literacy. J Gen Intern Med. 2005;20(2):175-84.

6. Jorm AF. Mental health literacy: empowering the community to take action for better mental health. Am Psychol. 2012;67(3):231-43.

7. Simmons MB, Hetrick SE, Jorm AF. Experiences of treatment decision making for young people diagnosed with depressive disorders:a qualitative study in primary care and specialist mental health settings. BMC Psychiatry. 2011;11:194.

8. Kelly CM, Mithen JM, Fischer JA, Kitchener BA, Jorm AF, Lowe A, Scanlan C. Youth mental health first aid: a description of the program and an initial evaluation. Int J Ment Health Syst. 2011;5(1):4.

9. Loureiro LM, Jorm AF, Mendes AC, Santos JC, Ferreira RO, Pedreiro AT. Mental health literacy about depression: a survey of portuguese youth. BMC Psychiatry. 2013;13:129.

10. Kaphingst KA, Weaver NL, Wray RJ, Brown ML, Buskirk T, Kreuter MW. Effects of patient health literacy, patient engagement and a system-level health literacy attribute on patient-reported outcomes: a representative statewide survey. BMC Health Serv Res. 2014;14:475. 
11. Berkman ND, Dewalt DA, Pignone MP, Sheridan SL, Lohr KN, Lux L, Sutton SF, Swinson T, Bonito AJ. Literacy and health outcomes. Evid Rep Technol Assess (Summ). 2004;(87):1-8.

12. van Onna $\mathrm{M}$, Hinsenveld $\mathrm{E}$, de Vries $\mathrm{H}$, Boonen $\mathrm{A}$. Health literacy in patients dealing with gout: a qualitative study. Clin Rheumatol. 2015;34(9):1599-603.

13. Matthiesen MI, Vela MB, Press VG. Health literacy during aging. J Gen Intern Med. 2015;30(12):1731

14. Levin-Zamir D, Peterburg Y. Health literacy in health systems: perspectives on patient self-management in Israel. Health Promot Int. 2001;16(1):87-94.

15. Thurston MM, Bourg CA, Phillips BB, Huston SA. Impact of health literacy level on aspects of medication nonadherence reported by underserved patients with type 2 diabetes. Diabetes Technol Ther. 2015;17(3):187-93.

16. Pulgarón ER, Sanders LM, Patiño-Fernandez AM, et al. Glycemic control in young children with diabetes: the role of parental health literacy. Patient Educ Couns. 2014;94(1):67-70.

17. Federman AD, Wolf MS, Sofianou A, O'Conor R, Martynenko M, Halm EA, Leventhal H, Wisnivesky JP. Asthma outcomes are poor among older adults with low health literacy. J Asthma. 2014;51(2):162-7.

18. Rust CF, Davis C, Moore MR. Medication adherence skills training for AfricanAmerican breast cancer survivors: the effects on health literacy, medication adherence, and self-efficacy. Soc Work Health Care. 2015;54(1):33-46.

19. Coles ME, Ravid A, Gibb B, George-Denn D, Bronstein LR, McLeod S. Adolescent mental health literacy: young people's knowledge of depression and social anxiety disorder. J Adolesc Health. 2016;58(1):57-62.

20. Stewart DW, Reitzel LR, Correa-Fernández V, Cano MÁ, Adams CE, Cao Y, Li Y, Waters AJ, Wetter DW, Vidrine JI. Social support mediates the association of health literacy and depression among racially/ethnically diverse smokers with low socioeconomic status. J Behav Med. 2014;37(6):1169-79.

21. Loureiro LM, Jorm AF, Oliveira RA, Mendes AM, dos Santos JC, Rodrigues MA, Sousa CS. Mental health literacy about schizophrenia: a survey of Portuguese youth. Early Interv Psychiatry. 2015;9(3):234-41.

22. Chari R, Warsh J, Ketterer T, Hossain J, Sharif I. Association between health literacy and child and adolescent obesity. Patient Educ Couns. 2014;94(1):61-6.

23. Champion JD, Harlin B, Collins JL. Sexual risk behavior and STI health literacy among ethnic minority adolescent women. Appl Nurs Res. 2013;26(4):204-9.

24. Kelo M, Martikainen M, Eriksson E. Self-care of school-age children with diabetes: an integrative review. J Adv Nurs. 2011;67(10):2096-108.

25. Melas PA, Tartani E, Forsner T, Edhborg M, Forsell Y. Mental health literacy about depression and schizophrenia among adolescents in Sweden. Eur Psychiatry. 2013;28(7):404-11.

26. Levin-Zamir D, Lemish D, Gofin R. Media health literacy (MHL): development and measurement of the concept among adolescents. Health Educ Res. 2011;26(2):323-35.

27. Department of Maternal and Child Health Care and Community Health, Chinese Health Education Network/Health News Communication Center, Ministry of Health. Report on the Health Literacy Survey of Chinese Residents. 2013. http://www.nhc.gov.cn/ewebeditor/uploadfile/2014/12/2 0141216161638598.pdf [2019-05-11]

28. Ran M, Peng L, Liu Q, Pender M, He F, Wang H. The association between quality of life (QOL) and health literacy among junior middle school students: a cross-sectional study. BMC Public Health. 2018;18(1):1183.

29. Tao FB, Hu CL, Sun YH, Hao JH. The development and application of multidimensional sub-health questionnaire of adolescents (MSQA). Chin J Dis Control Prev. 2008;12(4):309-14 (in Chinese with English abstract).

30. Huang L, Tao FB, Wan YH, Xing C, Hao J, Su PY, et al. Self-reported weight status rather than BMI may be closely related to psychopathological symptoms among mainland Chinese adolescents. J Trop Pediatr. 2011;57(4):307-11.

31. Wan YH, Xu SJ, Chen J, Hu CL, Tao FB. Longitudinal effects of psychological symptoms on non-suicidal self-injury: a difference between adolescents and young adults in China. Soc Psychiatry Psychiatr Epidemilo. 2015;50(2):237-47.

32. Tao FB, Xu ML, Kim SD, Sun Y, Su PY, Huang K. Physical activity might not be the protective factor for health risk behaviours and psychopathological symptoms in adolescents. J Paediatr Child Health. 2007;43(11):762-7.

33. Wu X, Tao S, Zhang Y, Zhang S, Tao F. Low physical activity and high screen time can increase the risks of mental health problems and poor sleep quality among Chinese college students. PLoS One. 2015;10(3):e0119607.

34. Deng F, Tao FB, Wan YH, Hao JH, Su PY, Cao YX. Early menarche and psychopathological symptoms in young Chinese women. J Women's Health (Larchmt). 2011;20(2):207-13.

35. Xu H, Sun Y, Wan Y, Zhang S, Xu H, Yang R, Wang W, Zeng H, Xu S, Hao J, Tao F. Eating pattern and psychological symptoms: a cross-sectional study based on a national large sample of Chinese adolescents. J Affect Disord. 2019;244:155-63.

36. Zhang SC, Wan YH, Tao SM, Chen J, Tao FB. Reliability and construct validity of the adolescent interactive health literacy questionnaire. Chin J Sch Health. 2014;35(3):332-6 (in Chinese with English abstract).

37. Zhang SC, Tao FB, Wu XY, Tao SM, Fang J. Low health literacy and psychological symptoms potentially increase the risks of non-suicidal selfinjury in Chinese middle school students. BMC Psychiatry. 2016;16(1):327

38. Zhang SC, Yang R, Li DL, Wan YH, Tao FB, Fang J. Association of health literacy and sleep problems with mental health of Chinese students in combined junior and senior high school. PLoS One. 2019;14(6):e0217685.

39. US. Department of Health and Human Services, Office of Disease Prevention and Health Promotion. National Action Plan to Improve Health Literacy. Washington, DC. 2010. https://health.gov/communication/hlactionplan/pdf/ Health_Literacy_Action_Plan.pdf. [2019-05-11].

40. Thomas S, Heinrich S, Kühnlein A, Radon K. The association between socioeconomic status and exposure to mobile telecommunication networks in children and adolescents. Bioelectromagnetics. 2010;31(1):20-7.

41. Zhou Q, Fan L, Yin Z. Association between family socioeconomic status and depressive symptoms among Chinese adolescents: evidence from a national household survey. Psychiatry Res. 2018;259:81-8.

42. Zhang SC, Wei CN, Fukumoto K, Harada K, Ueda K, Minamoto K, Ueda A. A comparative study of health-promoting lifestyles in agricultural and nonagricultural workers in Japan. Environ Health Prev Med. 2011;16(2):80-9.

43. Holt-Lunstad J, Smith TB, Layton JB. Social relationships and mortality risk: a meta-analytic review. PLoS Med. 2010;7:e1000316.

44. Cohen S, Underwood LG, Gottlieb BH. Social support measurement and intervention: a guide for health and social scientists. New York: Oxford University Press; 2000.

45. Dinis MAP, Sousa HFP, Moura A, Viterbo LMF, Pinto RJ. Health Behaviors as a Mediator of the Association Between Interpersonal Relationships and Physical Health in a Workplace Context. Int J Environ Res Public Health. 2019;16(13).

46. Kiecolt-Glaser JK, Gouin JP, Hantsoo L. Close relationships, inflammation, and health. Neurosci Biobehav Rev. 2010;35:33-8.

47. Petersen S, Brulin C, Bergström E. Recurrent pain symptoms in young schoolchildren are often multiple. Pain. 2006:121(1-2):145-50.

48. Carnes D, Parsons S, Ashby D, Breen A, Foster NE, Pincus T, Vogel S, Underwood M. Chronic musculoskeletal pain rarely presents in a single body site: results from a UK population study. Rheumatology (Oxford). 2007; 46(7):1168-70

49. Ahangar K, Mansor M, Juhari R. Interpersonal relationships and depression among adolescents living in Tehran's shelters. Int J Child Youth Family Stud. 2012;1:112-23.

50. Bailey SC. The mechanisms linking health literacy to behavior and health status. Am J Health Behav. 2011;35(1):118-28.

51. Wang H, Fu J, Lu Q, Tao F, Hao J. Physical activity, body mass index and mental health in Chinese adolescents: a population based study. J Sports Med Phys Fitness. 2014;54(4):518-25.

52. Kleppang AL, Hartz I, Thurston M, Hagquist C. The association between physical activity and symptoms of depression in different contexts - a crosssectional study of Norwegian adolescents. BMC Public Health. 2018;18(1):1368.

53. Jodkowska M, Oblacińska A, Tabak I, Radiukiewicz K. Differences in dietary patterns between overweight and normal-weight adolescents. Med Wieku Rozwoj. 2011;15(3):266-73.

54. Hou F, Xu S, Zhao Y, Lu Q, Zhang S, Zu P, Sun Y, Su P, Tao F. Effects of emotional symptoms and life stress on eating behaviors among adolescents. Appetite. 2013;68:63-8.

55. Sharma S, Nagar S, Chopra G. Health awareness of rural adolescent girls:an intervention study. J Soc Sci. 2009;21(2):99-104.

56. Delaney FG. Nursing and health promotion; conceptual concerns. J Adv Nurs. 1994;20:828-35.

57. Zhang SC, Tao FB, Ueda A, Wei CN, Fang J. The influence of healthpromoting lifestyles on the quality of life of retired workers in a mediumsized city of northeastern China. Environ Health Prev Med. 2013;18:458-65.

\section{Publisher's Note}

Springer Nature remains neutral with regard to jurisdictional claims in published maps and institutional affiliations. 